Pobrane z czasopisma New Horizons in English Studies http://newhorizons.umcs.pl Data: 26/04/2023 04:19:59

New Horizons in English Studies 2/2017

\title{
LITERATURE
}

$\infty$

\section{Magdalena Solarz}

Maria Curie-Skeodowska University (UMCS) in Lublin

MAGDALENA@SOLARZ.EU

\section{The Labyrinth as an Anti-Home in Mark Z. Danielewski's House of Leaves}

\begin{abstract}
This paper examines the spatial model of a house as a labyrinth in Mark Z. Danielewski's experimental novel House of Leaves in relation to Yuri M. Lotman's concept of an anti-home.

The aim of the paper is to analyze the spatial organization of the house presented in the novel and its influence on the characters. It also examines the connection between the mental state of the inhabitants and the changing nature of the labyrinth by demonstrating how the subversive spatiotemporal organization of domestic space accounts for the transformation of the novel's protagonists.
\end{abstract}

Keywords: Mark Z. Danielewski, House of Leaves, home, anti-home, labyrinth

\section{Introduction}

House of Leaves, the first novel by Mark Z. Danielewski, is an unconventional work of fiction that, just like the house presented in it, "resists interpretation" (Danielewski 2000, 356). The novel is cross-referenced with an album Haunted by Danielewski's sister, Poe, and followed by an epistolary novella The Whalestoe Letters, which consists of letters that Pelafina $\mathrm{H}$. Lièvre writes to her son, Johnny Truant. Because of its ambiguity, it is difficult to categorize House of Leaves as any specific genre. To make matters even more complicated, the novel has an unusual layout due to the author's experiments with typography, such as colored fonts, crossed out fragments of text, blank pages, graphics, or footnotes within footnotes.

When it comes to the narrative, House of Leaves has a Chinese box structure with four layers of narration. The first one is the story of a Pulitzer Prize-winning photo- 
journalist, Will Navidson, his partner and a former model, Karen Green, and their two children, presented in a form of a documentary film made by Navidson himself and titled The Navidson Record. The plot of the film focuses on the family's efforts to settle into a new life in a house on Ash Tree Lane somewhere in Virginia. However, the discovery of a mysterious hallway leading to a labyrinth inside the house as well as the fact that the house's interior is by one-fourth of an inch bigger than its exterior complicate this process.

The Navidson Record is later analyzed by an elderly blind man called Zampanò. His academic study of the film is put together in a book titled House of Leaves and creates the second layer of narration. After Zampanò's death, his project is found by Johnny Truant, a young tattoo artist, who decides to "give the raw material a more organized form" (Hamilton 2008, 4). ${ }^{1}$ Johnny's comments on Zampanò's work and his doubts about the authenticity of the documentary mixed with many stories from his life create the third level of narration in the form of footnotes and the introduction to the book. The last layer is made of the footnotes added by the unknown editors to both Johnny's and Zampanò's texts. To differentiate all the voices in the book Danielewski uses separate fonts for each layer of narration. Zampanò's project is written in Times New Roman, Johnny Truant's story appears in Courier, and the editors use Bookman.

The multiple narrators, non-existing sources, which are cited by Zampanò, footnotes referring to other footnotes, or the unusual typography of the pages, which sometimes reflects the plot and the setting of the house on Ash Tree Lane, create the effect of a maze in which the reader can get lost. Therefore, the concept of a labyrinth is not only used as the setting of the story, but also as the way in which the documentary and the text itself are structured. However, for the sake of clarity, in this paper I am going to focus only on the structure and function of labyrinth inside the house as presented in The Navidson Record.

The concept of a labyrinth, which becomes the basis for the spatial organization of the house in the novel, reflects Yuri M. Lotman's concept of an anti-home. The irrational labyrinth inside the house on Ash Tree Lane, just as an anti-home, is an uninhabitable space which stands in opposition to the idea of a secure and cosy home that, according to Lotman, is supposed to be "the centre and focus of the world order" $(2001,97)$. It should be a familiar place that offers shelter to its inhabitants and protects them from the chaos and danger of the outside world. It is also "considered to be a female sphere and is connected with the cult of domesticity" (Majlingová 2011, 23). Thus, when the house defies rationality and starts to represent the numinous, "which is something that transcends human reason (but which need not be the supernatural)" (Aguirre 2008, 2), it fails to serve as a safe haven and can no longer be considered

Because Johnny Truant finds the project in the form of various notes and loose pieces of paper it is impossible to state to what extent he is responsible for the final form and content of the text attributed to Zampanò. 
a home. It is transformed into an anti-home, which Lotman describes as "the centre of an abnormal world" $(2008,186)$.

The distinction between a home and an anti-home resembles a division of Gothic space into a "domain of rationality" and the space of the Other. These two spheres are divided by limen - a threshold or a boundary, which according to Manuel Aguirre, is not a line but an area that "is a part of the Other" $(2008,2)$. The threshold divides and connects these two spheres at the same time. Furthermore, the characters who are contemplating crossing the line are already on the other side. The space of the Other, thus, is a dangerous force that seems to expand and take over its borders.

Another concept which has to be mentioned when examining the house in The Navidson Record is that of Sigmund Freud's "uncanny," which is also described by Danielewski in the footnotes of House of Leaves. The narrator discusses different theories of the concept, which comes from the German word "unheimlich" and is translated into English "uncanny" as well as "unhomely." The ambiguous meaning of the word is explained in the novel as something that evokes fear, "[t]hus that which is uncanny or unheimlich is neither homely not protective, nor comforting nor familiar. It is alien, exposed, and unsettling, or in other words, the perfect description of the house on Ash Tree Lane" (Danielewski 2000, 28). Moreover, the uncanny feeling can be caused by "intellectual uncertainty" (Bemong 2003) connected with the lack of orientation in the house. It can also represent a sudden return of something that is already known, but repressed.

\section{The house as labyrinth}

When it comes to the spatial organization, the house presented in The Navidson Record is made of two contrasting spaces divided by the liminal area in the form of an entrance to the hallway. In effect, on the one hand, the house on Ash Tree Lane is a family home. On the other hand, it contains a labyrinth which, because of its irrational appearance, violates domesticity and is a source of fear for its inhabitants. When Navidson and his team decide to explore the hallway they cross the boundary and begin to investigate the space of the Other, leaving the familiar reality behind.

The numinous space in the novel is characterized by absence. During the explorations the characters discover that all parts of the labyrinth, despite constant changes, share one important feature: they are empty inside. The characters walk through endless hallways only to find that there is nothing there. The labyrinth is utterly dark and, with the exception of the sound of a growl, completely silent. The temperature inside equals zero and there is no air movement. Furthermore, as proved by Karen, Tom, and Holloway, using a compass is pointless because it seems that north "has no authority there" (Danielewski 2000, 90).

Discrepancies in measurements of the house on Ash Tree Lane distort the sense of space and stability. The fact that, after the appearance of a mysterious hallway, the 
width of the house inside is larger by one-fourth of an inch than that on the outside leads to anxiety and disorientation of the characters. Although Navidson and his friends try various methods of measuring the house, the result remains the same. They cannot find a reasonable explanation for what Reston (a friend of the family) "keeps referring to as 'a goddamn spatial rape"' (Danielewski 2000, 55). To complicate matters even further, the difference in measurements later expands to five-sixteenths of an inch; then it vanishes completely only to reappear as "at least foot long" (Danielewski 2000, 40) space between Karen's shelves and a wall, which evokes more terror and frustration.

Furthermore, it is impossible to create a layout of the house not only because of the wall-shifts, but also due to the way in which Navidson shot and edited his film. Many jump cuts lead to a lack of continuity and confusion. When the characters explore the labyrinth during one of the explorations of the hallway, which Navidson titles Exploration \#4, they try to make sense of the purpose of the place, but they are unable to find any definite answer. In his analysis of Navidson's footage, Zampanò also considers different possibilities, such as an aberration of physics, prison, or a hideaway, but he also fails to find any solution. It may be due to the fact that the house lacks a center, which in Derrida's understanding is a concept necessary to "orient, balance, and organize the structure." As he claims, "(...) even today the notion of a structure lacking any center represents the unthinkable itself" (quoted in Danielewski 2000, 112). In other words, the human mind needs the concept of a center in order to make sense of a surrounding reality. The numinous in Danielewski's novel is, then, depicted as something that cannot be logically understood and disrupts the sense of orientation of the characters.

As it turns out, it is as difficult to find directions inside the labyrinth as it is to inhabit it. As Will Slocombe suggests, "[t]he House symbolizes absence and to live inside absence is impossible" $(2015,92)$. This feature is visible in the architecture of the house as well as in the form of the novel. As Danielewski writes in an epigraph to Chapter XX:

The walls are endlessly bare. Nothing hangs on them, nothing defines them. Even to the keenest eye or most sentient fingertip, they remain unreadable. You will never find a mark there. No trace survives. The walls obliterate everything. They are permanently absolved of all record. Oblique, forever obscure and unwritten. Behold the perfect pantheon of absence. $(2000,423)$

This description appears in faux Braille, which instead of being a set of tangible dots is simply printed on a page with the use of ink. The text is, thus, "simultaneously there, present on the page, and yet absent," which makes it as illegible as the walls of the house (Boothroyd 2015, 22).

Similarly, in chapter IX, titled "The Labyrinth," the nothingness that defines the space on Ash Tree Lane is represented by the way in which its descriptions are placed on the pages. During the Exploration \#4 Holloway makes a hole in one of the walls, hoping to find an exterior, but what he sees instead is another empty room, which leads 
to a "hallway spawning yet another endless series of empty rooms and passageways, all with walls potentially hiding and thus hinting at a possible exterior, though invariably winding up as just another border to another interior" (Danielewski 2000, 119). This event has its visual representation in the form of the footnote number 144, which begins next to the description of Holloway's actions and continues for several pages with the text on every other page being a mirrored image of the previous one. A blue box containing a list of objects that are not in the house creates a hallway through the book resembling the one in the story. Therefore, the typography of the pages makes the reader experience reading the book like the protagonist who loses his sense of orientation in the labyrinth.

According to Ryan Jones, the house can be treated as "nothing which, based on human perception, makes it everything we can imagine" $(2014,9)$. This nothingness is represented in the aforementioned footnote number 144 that perfectly manifests the endlessness and absence of the labyrinth. The blue borders of the footnote can be associated with blue screens used in chroma keying, which is a technique in video post-production used to remove the background of a picture or a video in order to combine two frames together. Therefore, the house, just as a blue screen, functions as a "blank slate" (Boothroyd 2015, 20) onto which something may be projected.

\section{The protagonists}

If the labyrinth inside the house can be treated as a blank slate, then the individuals who explore it are the ones who paint its walls with their own personality. One of Zampanò's invented critics claims that the anomalies of the house mirror the psyche of the inhabitants: "The house, the halls, and the rooms all become the self-collapsing, expanding, tilting, closing, but always in perfect relation to the mental state of the individual" (Danielewski 2000, 165). Therefore, the dark hallways or the monster inside the labyrinth are projections of fears of the explorers. The darkness of the hallways serves as an isolation tank in which the characters are forced to face their inner demons: "Due to the wall-shifts and the extraordinary size, any way out remains singular and applicable only to those on that path at a particular time. All solutions then are necessarily personal" (Danielewski 2000, 115). In other words, everyone who enters the house experiences it in a different way. The state of mind of the individuals is responsible for the problems they encounter on the way. As a result, some of the explorers emerge from the labyrinth transformed, while others are consumed by it.

The person who is most affected by Ash Tree Lane is the main protagonist, Will Navidson. His attitude towards the house quickly changes from the initial fear into the desire to master the unknown, as the house captures all of his attention. He enters the hallway out of curiosity, which cannot be satisfied due to the endless lack of answers. His fascination with the labyrinth proves so strong that eventually he decides to return to Ash Tree Lane without any help, despite the traumatic experience he had there. As 
one of the imagined scholars suggests, he became "possessed by some self-destructive notion to go back there and yet completely dispossessed of any rational mechanism to override such an incredibly stupid idea" (Danielewski 2000, 386).

For Navidson, the labyrinth is also an adventure and a possibility to make his film more intriguing. The mysterious hallway offers a familiar feeling of danger and excitement to which he is accustomed as a former war photographer, and which he lacks since moving to Virginia. Documenting the darkness and uncanny qualities of the place is also a challenging task for a photographer, which, to someone as ambitious as Navidson, is an incredibly alluring idea. Thus, his subsequent decision to return to the house may be an indication of his dissatisfaction with the previous footage and of the need to improve the quality of the film. Likewise, going back alone may be explained by the fact that in this way he "produced his best work" (Danielewski 2000, 419).

Consequently, Navidson is transformed by the experience of the labyrinth. As a result of the terror caused by the anti-home, his initial curiosity and excitement turn into an emotional trauma:

After all in a very short amount of time Navidson had seen the rape of physics. He had watched one man murder another and then pull the trigger on himself. He had stood helplessly by as his own brother was crushed and consumed. And finally he had watched his lifelong companion flee to her mother and probably another lover, taking with her his children and bits of his sanity. (Danielewski 2000,395)

All of these events lead to the protagonist moving out of the house. Even though he remains focused on examining samples from the labyrinth, "[n]othing matters anymore to him" $(2000,397)$. Surprisingly, even the recording of Karen's infidelity has no effect on him since his only concern is going back to the house.

Navidson's return to Ash Tree Lane is motivated by various factors. First of all, he goes back to the labyrinth because he is haunted by guilt after the death of his brother Tom, who sacrificed himself to save Daisy, Will's daughter. After the tragic event Will could not come to terms with the horror that he witnessed and the fact that he "stood helplessly" while the house killed his twin (Danielewski 2000, 395). The impact of the tragic experience stems partly from the loss of a family member, but also from the fact that it was not the first time that Navidson watched someone in danger, without being threatened himself. As it is revealed in the letter, Will wrote to Karen before returning to Ash Tree Lane; while working in Sudan he encountered Delial, "a Sudanese child dying of starvation, too weak to move even though a vulture stalk[ed] her from behind" (Danielewski 2000, 368). ${ }^{2}$ Navidson's photo of Delial won the Pulitzer prize and brought him recognition. However, it was also a symbol of his powerlessness and

2 Navidson's photograph of Delial is “based on Kevin Carter's 1994 Pulitzer Prize-winning photograph of a vulture preying on a tiny Sudanese girl who collapsed on her way to a feeding center" (Danielewski 2000, 368). 
failure, because instead of helping the child and "offering her what little comfort he may have been able to provide" he only took the photo (Hamilton 2008, 6). The letter, which lacked punctuation and was full of spelling mistakes, revealed his emotional state and explained that going back to the house was treated by him as a "penance" for his previous passiveness (Danielewski 2000, 391).

Finally, going back to the house is also connected with the risk of dying. Navidson feels responsible for the deaths caused by the house and believes that he was "the one who should have died" (Danielewski 2000, 387). As a war photographer he often found himself in life-threatening situations; however, he was never at risk because there was always something or someone between him and the threat. His last visit to the house is, thus, completely different from other explorations, because this time he goes there alone. For him "[r]eturning to Ash Tree Lane meant removing the other" (Danielewski 2000, 422). In other words, it meant standing face-to-face with danger that awaited him in the house, without putting anyone else at risk. In effect, the anti-home serves as a catalyst that pushes Navidson to confront the traumatic experiences of the past and deal with their consequences.

The house has a completely different effect on Karen, whose idea of coping with the inexplicable events inside the house is manifested in her attempt to domesticize the place. She becomes interested in Feng Shui and decides to build bookshelves for her books, to which she refers as "newly found day to day comfort" (Danielewski 2000, 34). Her project can be considered as a sign of denial, because in her insistence on normality she intentionally avoids the uncanny space, treating it like something which may disappear on its own. However, her behavior may be also a sign of maturity which, according to Zampanò, "has everything to do with the acceptance of "not knowing"" (Danielewski 2000, 34). Instead of obsessing over the hallway which "offers no answers" (Danielewski 2000, 60), Karen accepts the meaninglessness of it and focuses on her family.

Unlike Navidson, Karen is the responsible one who disapproves of risk-taking and insists on keeping the family safe and happy. She repeatedly warns Navidson that she will move out if he keeps insisting on exploring the labyrinth. She is also the one to whom Tom, after the Exploration \#4, gives four keys to a steel door to the hallway. By doing that he attempts "to offer Karen some measure of control, or at least sense of control, over the horror beyond the door" (Danielewski 2000, 340). However, at this point in the story, although she is grateful to Tom, his gesture does not stop her from wanting to escape from the house.

Apart from being a source of distress, the house also allows Karen to overcome her dependence on Navidson. She becomes more self-reliant; during the rescue mission which follows Exploration \#4 she manifests her coming out of denial by monitoring the radios and throwing away the rest of her Feng Shui items. Moreover, she is also the one who makes the decision about moving out of the house and does not allow anyone to alter her mind. When alone in New York, Karen travels through her own inner maze by editing Navidson's footage. As a result, she makes two short films, one of which she titles A Brief History of Who I Love. In her project she incorporates pieces from Navid- 
son's life, such as his childhood pictures or photos he took, including the one of Delial. Karen's film is deliberately not dealing with the house; instead, its focus lies on what she describes as "what ... that wicked place stole from me" (Danielewski 2000, 366), revealing that Navidson is the one she values the most. By working on these films she is able to finally understand her partner. Furthermore, the creative process helps her diminish the side effects of the exposure to the house, such as insomnia or panic attacks.

Different approaches to the transformation of Ash Tree Lane from a home into an anti-home are a source of tension between the family members. At the beginning, moving to Virginia was supposed to help the Navidsons with repairing their relationship, but it quickly became the reason behind their separation. In one of the video journal entries, which Karen records after Navidson's disappearance, she says: "[t]his house, this home, was supposed to help us get closer. It was supposed to be better and stronger than some stupid marriage vow. It was supposed to make us a family. [sobbing] But, oh my god, look what's happened" (Danielewski 2000, 321).

Karen and Will gradually become more and more distant towards each other, because of their contrasting attitudes towards what is happening on Ash Tree Lane: Karen focuses on the domestic space of their house, Navidson on the mysterious part of it. He insists on getting answers and conquering the unknown, whereas his partner tries to stay as far away from the hallway as possible. She refuses to participate in the explorations and wants Navidson to do the same. "II don't care,' she tells Navidson. 'Stop drilling holes in my walls"' (Danielewski 2000, 30).

As Will becomes more immersed in the explorations, Karen falls into indifference. The lack of communication and understanding puts more strains on their relationship. Although Karen and Will claim to love each other, they are unable to express their feelings to one another. Instead, they reveal them in video journal entries. Karen explains that she is afraid of the hallway and does not want her partner to go in there because she loves him. At the same time, Navidson claims that investigating the labyrinth is what he desires the most, but stops himself from going there out of love for Karen (Danielewski 2000, 62). As a result, they both think that their needs are being neglected by the other person:

[F]inally the lack of physical intimacy and emotional understanding leads both of them to make privately voiced ultimatums.

Karen: But I will say this, if he goes in there, I'm outta here. Kids and all.

Navidson: If she keeps up this cold front, you bet I'm going in there. (Danielewski 2000, $62-63)$

The growing distance between them is also visible in the footage from the Exploration \#4 during which "not once are they shown in the same frame together" (Danielewski 2000, 101).

However, the negative influence the anti-home has on Will and Karen is also precisely the factor that helps them get back together. When Navidson decides to explore 
the labyrinth alone, Karen, although still terrified of Ash Tree Lane, forces herself to go back there to find her lover. As Zampanò suggests, "[w]hatever ultimately allows Karen to overcome her fears, there is little doubt her love for Navidson is the primary catalyst" (Danielewski 2000, 522). She manages to save him by proving that her love is stronger than the inner demons she has to face. Similarly, Navidson also manifests his love for Karen. First, when he carries her out of the collapsing bedroom, despite his exhaustion caused by the exposure to the hallway. Secondly, in the letter which he writes before his departure for the final exploration of the labyrinth, he declares that he loves and misses her. Furthermore, one of Zampanò's sources argues that Navidson's final word in the house is "[h]is only hope, his only meaning: 'Karen"” (Danielewski 2000, 523).

As it is the case with her partner, the house seems to respond to Karen's mind and give her exactly what she is looking for. In an interview she confesses that during their final encounter with the labyrinth she was able to find Navidson simply by thinking about him. Moreover, they were able to escape from the hallway because "the house just dissolved" when they were finally together (Danielewski 2000, 524). As Natalie Hamilton claims, "their love for each other brought them safely out of their individual labyrinths" (Hamilton 2008, 7). The house forces them to confront the darkest parts of themselves in order to achieve a happy ending. As it turns out, the appearance of the labyrinth, which transformed the house from a safe haven that they hoped for into a labyrinth that traumatized them, is exactly what they needed to get closer as a family.

Apart from an unexpected happy ending, the novel ends with the reversal of the protagonists' roles. At the beginning Will Navidson is seen as the stronger and more dominant one. Paralyzed by fear, Karen is characterized by insecurity and neediness. However, because of the house, she slowly frees herself from the dependence on Navidson, who eventually becomes the one who needs saving. By managing to overcome her fears and come to her lover's rescue, the female protagonist not only proves that she is no longer the weaker one, but also becomes responsible for their survival.

\section{Conclusion}

To conclude, House of Leaves presents a postmodern vision of a haunted house that fails to fulfill its role as a domestic space due to the uncanny labyrinth inside. Because of the changing nature of the numinous labyrinth, which adapts itself to the psyche of the ones who enter it, there is no possibility to find any permanent solution to the mystery of the house. Everyone who travels through its corridors has a unique experience and must face different obstacles. The space terrorizes its inhabitants and forces them to reflect not only on the structure of the place in which they live, but also on their own mental condition that appears to be mirrored by the house. "All solutions then are necessarily personal" (Danielewski 2000, 115), because in the dark hallway everyone 
is forced to find a way out on their own by overcoming their fears and solving their problems. The anti-home is, thus, simultaneously a cause of Navidsons' problems, a reflection of the tension between them as well as the place that transforms them.

\section{References}

Aguirre, Manuel. 2008. "Geometries of Terror: Numinous Spaces in Gothic, Horror and Science Fiction.” Gothic Studies 10 (2): 1-17.

Bemong, Nele. 2003. "Exploration \# 6: The Uncanny in Mark Z. Danielewski's 'House of Leaves." Image \& Narrative.

http:/www.imageandnarrative.be/inarchive/uncanny/nelebemong.htm.

Boothroyd, David. 2015. "Metaleptic Transgression and Traumatic Experience: The 'empty Rooms, Long Hallways, and Dead Ends' of House of Leaves.” Lund: Lund University. http://lup.lub.lu.se/student-papers/record/7445282.

Danielewski, Mark Z. 2000. House of Leaves. 2nd edition. New York: Pantheon.

Hamilton, Natalie. 2008. "The A-Mazing House: The Labyrinth as Theme and Form in Mark Z. Danielewski's House of Leaves." Critique: Studies in Contemporary Fiction 50 (1): 3-16. doi:10.3200/CRIT.50.1.3-16.

Jones, Ryan. 2014. "Labyrinthine Literature: Reality versus Perception in Mark Z. Danielewski's House of Leaves" Scribd.

https://pl.scribd.com/document/304168593/Labyrinthine-Literature-Reality-versus-Perception-in-Mark-Z-Danielewski-s-House-of-LeavesLabyrinthine-Literature-Reality-versus-Perception-in-Mark.

Lotman, Yuri. 2001. Universe of the Mind: A Semiotic Theory of Culture. Bloomington: Indiana University Press.

Majlingová, Veronika. 2011. "The Use of Space in Gothic Fiction.” Master's Thesis, Brno: Masaryk University, Faculty of Arts.

https://theses.cz/id/h0tty6?furl=\%2Fid\%2Fh0tty6;so=nx;lang=en.

Slocombe, Will. 2015. "This Is Not For You': Nihilism and the House That Jacques Built." MFS Modern Fiction Studies 51 (1): 88-109. doi:10.1353/mfs.2005.0015. 